\title{
Labeling Requirements for Alaska Seafood
}

Processors

This Sea Gram addresses the legal and regulatory requirements for labeling seafood products in Alaska. It is intended as guidance for the commercial seafood processing sector.

Both the U.S. Food and Drug Administration (FDA) and the Alaska Department of Environmental Conservation (DEC) require that seafood products be labeled before sale. New seafood safety regulations now require a Hazard Analysis Critical Control Point (HACCP) plan for all seafood products. Allergens are one of the hazards identified in the new Fish and Fishery Products Hazards and Controls Guidance. ${ }^{1}$ To address the allergen hazard and other newly enacted laws, proper documentation of product labeling must be written into a HACCP plan. This Sea Gram provides basic information, and relevant state and federal regulations for labeling seafood products.

Seafood labeling requirements in Alaska are described in the Alaska Administrative Code (AAC), Title 18, Chapter $34 .^{2}$ These regulations may not entirely apply if the seafood product is "for export only."3 The AAC incorporates the federal regulations, which cover a wide variety of foods, including information on nutritional labeling of food products. ${ }^{4}$

\section{Language and Placement of Label}

All labels must be in English, with a few exceptions. ${ }^{5}$ However, one can use multilingual labels in addition to English.

Depending on the box or carton size, and whether the individual packages are for retail or wholesale trade, each package (if for retail sale), and each fish box (if for wholesale), must be marked at the time of sealing with the date of packaging. ${ }^{6}$

1 Fish and Fishery Products Hazards and Controls Guidance (4 ${ }^{\text {th }}$ edn.), Food and Drug Administration, April 2011, http://ow.ly/fscY7.

2 These regulations are typically cited as 18 AAC 34.

3 Title 18, Chapter 34, Section 110 of the Alaska Administrative Code (18 AAC 34.110(a), "Unless a seafood product is for export only, a processor shall label seafood products as required under this section."

418 AAC 34.010 (incorporating 21 CFR 101.15). The federal regulations are typically cited as the Code of Federal Regulations, or CFRs.

518 AAC 34.110 (b).

618 AAC 34.110 (c).

by Izetta Chambers, J.D. Alaska Sea Grant Marine Advisory Program University of Alaska Fairbanks Bristol Bay Campus Dillingham, AK 99576 (907) 842-5692 izetta.chambers@alaska.edu

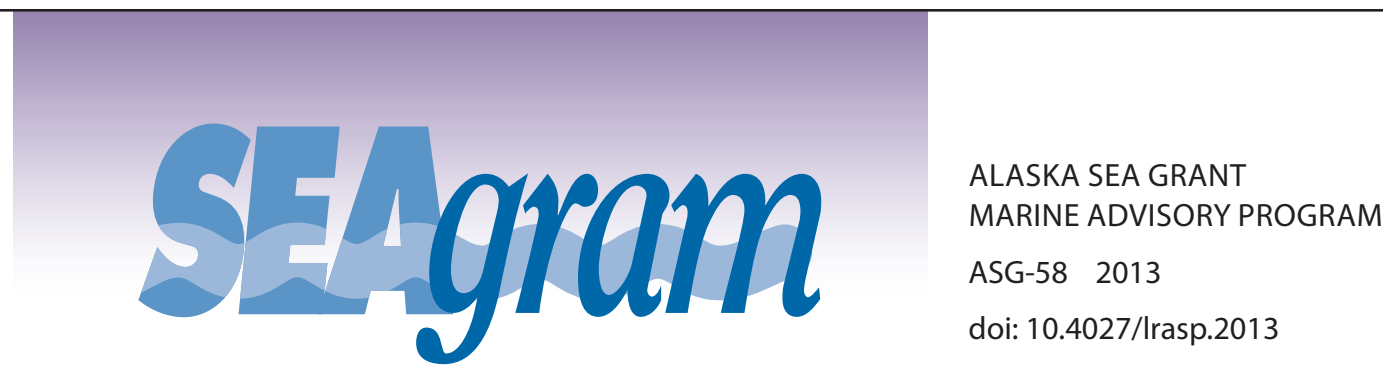


Unloading sea urchins into crates in Kechikan, Alaska. Photo by Gary Freitag, Alaska Sea Grant Marine Advisory Program.

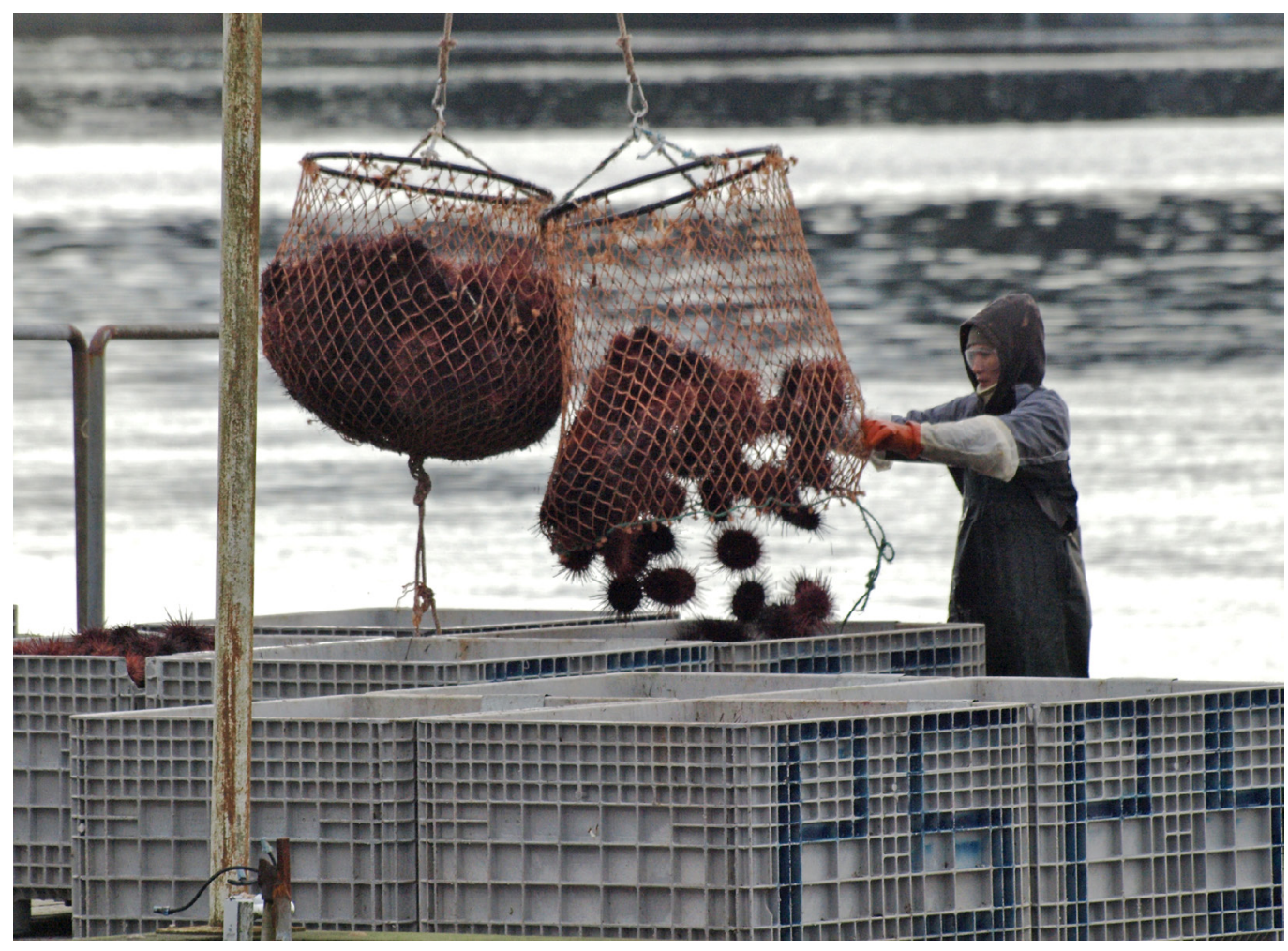

Before distribution, at least one $\operatorname{area}^{7}$ of the master carton (or fish box) and retail container must be labeled with the following information:

1. The Alaska Department of Environmental Conservation permit number (otherwise known as an "AK \#").

2. The date of packaging of the seafood product.

3. The name and address of the processor, packer, or distributor. If the seafood product was not processed by the person whose name appears on the label, the name on the label must be qualified by a phrase that reveals the connection that the person has with the seafood product (for example, "Manufactured for," "Distributed by," "Processed for," or "Packed for" and the name of the company responsible for distributing the product. The processor's permit number (AK\#) must appear somewhere on the packaging label.

4. The net weight or measure of the contents of the seafood package (the processor's scale must be certified by the Alaska Department of Transportation, Division of Weights and Measures).

5. The name of the seafood product approved by DEC or a market or common name as specified in FDA seafood list (e.g., King or Chinook Salmon, Chum or Keta Salmon, Coho or Silver Salmon, Pink or Humpback Salmon, Sockeye or Red Salmon). ${ }^{8}$

6. The common or usual name of each food ingredient, if the seafood product is made from two or more ingredients. Spices, flavorings, and colorings may be so designated without naming each one, except that each artificial flavoring, artificial coloring, or chemical preservative must be specifically identified.

7 For specific information on placement, size, and orientation of the Principal Display Panel, Alternate Principal Display Panel, and Information Label, refer to the Food, Drug, and Cosmetic Act, 21 USC \$301 et seq (June 25, 1938), and the Fair Packaging and Labeling Act, 15 USC 1451 et seq (July 1, 1967).

8 The Seafood List, FDA's Guide to Acceptable Market Names for Seafood Sold in Interstate Commerce 1993, http://ow.ly/fshi1. 
7. A listing, in order of predominance by weight in the product, of each food ingredient. However, ingredients present in amounts of two percent or less by weight need not be listed in order of predominance by weight, if a listing of those ingredients is placed at the end of the ingredient statement following an appropriate qualifying statement. An appropriate qualifying statement includes "Contains percent or less of [name of ingredient]" or "Less than percent of [name of ingredient]."

8. The word "IMITATION" if the container holds an imitation seafood product. Under the requirement of this paragraph (e.g., Imitation Crab Meat), the name of each seafood product imitated must be listed immediately after the word "IMITATION" and the word "IMITATION" must appear in letters at least as large as the name of the product. ${ }^{9}$

9. A holding statement, as appropriate considering the type of seafood product, and in compliance with the following requirements:

a. If the seafood product is not shelf-stable, the label must bear the holding statement "KEEP REFRIGERATED AT OR BELOW $40^{\circ} \mathrm{F}$ ” or "KEEP FROZEN BELOW $32^{\circ} \mathrm{F} . "$

b. If the seafood is not commercially sterile and is packaged in a reduced oxygen package or a modified atmosphere package, the label must bear the holding statement "KEEP REFRIGERATED BELOW $38^{\circ} \mathrm{F}$ ” or "KEEP FROZEN."

c. If the smoked finfish seafood product is not commercially sterile and is packaged in a reduced oxygen package or a modified atmosphere package, and if each package

i. Contains 3.5 percent water phase salt, contains (if allowed by 21 CFR 172.175, adopted by reference in 18 AAC 34.010) both 3.0 percent water phase salt and not less than $100 \mathrm{ppm}$ nitrite, contains other suitable barriers to control Clostridium botulinum, or is equipped with a time temperature indicator, the label must bear the holding statement "KEEP REFRIGERATED BELOW $38^{\circ} \mathrm{F}$ " or "KEEP FROZEN," or

ii. Does not contain 3.5 percent water phase salt, does not contain both 3.0 percent water phase salt and not less than $100 \mathrm{ppm}$ nitrite, does not contain other suitable barriers to control Clostridium botulinum, or is not equipped with a time temperature indicator, the label must bear the holding statement "KEEP FROZEN, THAW UNDER REFRIGERATION IMMEDIATELY BEFORE USE."10

d. The holding statement must be in letters at least one-eighth inch high and comparable in size and style to other label lettering.

e. Upon application by the processor, DEC will approve the removal of a holding statement as required under this paragraph

i. for a seafood product that is not thermally processed, or for a pickled seafood product that meets the requirements of 21 CFR 114.3-21 CFR 114.100, adopted by reference in 18 AAC 34.010, and

921 CFR 101.3(e), adopted by reference in 18 AAC 34.010 states that the packaged food must contain, "[t] he common or usual name of the food; or, in the absence thereof, (3) An appropriately descriptive term, or when the nature of the food is obvious, a fanciful name commonly used by the public for such food." 1018 AAC 34.101(c) (8) (B) (i) and (ii). 
ii. if the testing conducted under 18 AAC 34.125 demonstrates that the seafood product meets the requirements of that section and 18 AAC 34.122 for shelfstable seafood products.

10. The words "PREVIOUSLY FROZEN" if the container holds a seafood product that has been previously frozen and thawed and that will be sold without further processing; the words "PREVIOUSLY FROZEN" must appear in letters of sufficient size and prominence to be easily read under normal conditions of sale.

A box carton or other container of a seafood product intended for domestic processing, labeling, or repacking at another facility is exempt from some of the DEC labeling requirements, so long as the product meets the requirements for exceptions to the labeling regulation. ${ }^{11}$ It is recommended that a catcher-seller or anyone holding a Direct Market permit contact DEC for specific requirements. For example, if a CatcherSeller, authorized by the Alaska Department of Fish and Game has the applicable Catcher-Seller permit issued by ADFG to engage in sales of their own seafood product, they may work with a wholesale fish buyer and utilize that processor's DEC processor number on their packaging, if that is where the fish ultimately will be processed and packaged. However, a Catcher-Seller would still be required to obtain a Transporter's permit. The permit application is online. ${ }^{12}$

Below is a sample seafood product label that may be modified to fit most small seafood processing operations.

\section{ABC Fish Company \\ P.O. Box 0, Anytown, AK 996XX}

[YOUR LOGO HERE]

Frozen Wild Alaskan Sockeye Salmon

AK \#

Date of packaging:

Weight:

KEEP FROZEN

REFRIGERATE DURING THAWING

\section{Labeling of Custom Processed Seafood Products}

At the top of page 5 is a sample of a label that a custom processor might affix to a product intended for sale by another company, such as a direct market fisherman. One thing to note on the label is that the AK \# refers to the processor, not the fisherman. It references where the product was processed. It is not necessary to include the name or address of the processor, only their AK \#. ${ }^{13}$

1118 AAC 34.100 (c)(2), (3), (5), (6), and (7) (Labeling Requirements); 21 CFR 101.100(d)(1) and (2)

(Food; exemptions from labeling).

12 Alaska Department of Fish and Game, Commercial Fish Transporters, http://www.adfg.alaska.gov/ index.cfm?adfg=fishlicense.transporters (accessed February 2013).

13 Comments by Mike Gentry, Alaska Department of Environmental Conservation, Seafood Permitting (March 2013). 


\section{Processed for}

F/V Fishmonger, LLC

[YOUR LOGO HERE]

Frozen Wild Alaskan Sockeye Salmon

AK \#

Date of packaging:

Weight:

KEEP FROZEN

REFRIGERATE DURING THAWING

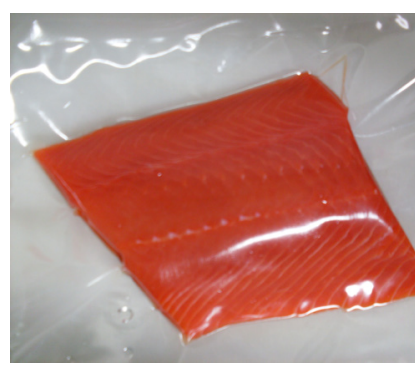

Having unlabeled product in your processing plant is a violation of DEC regulations.

\section{Nutritional Labeling}

The U.S. FDA requires nutritional labeling of food products for human consumption. ${ }^{14}$ Exemptions to this requirement are allowed for firms with fewer than 10 employees and who produce less than 10,000 units of specific products. For processors with between 10 and 100 employees and who produce 10,000 to 100,000 units, a processor is eligible to file for the small business exemption. Small businesses wishing to file an annual notice of exemption from the nutrition labeling requirements can do so online at http:// www.fda.gov/Food/LabelingNutrition/FoodLabelingDuidanceRegulatoryInformation/ SmallBusinessNutritionLabelingExemption/default.htm. If you fall outside of this sales threshold, you may be able to obtain the nutritional information through the Alaska Seafood Marketing Institute, by sending samples to a nutritional analytical testing laboratory, or through the USDA. ${ }^{15}$ Nutritional analyses have been completed on many of the common Alaska seafood species, and you may be able to get this information to comply with the nutritional labeling requirement at little to no cost. Please note: if a firm makes a nutritional claim, regardless of its size, it must have a nutritional label as required under the Nutrition Labeling and Education Act (NLEA) of 1990. ${ }^{16}$

Exemptions to this requirement must be re-filed yearly. If the firm sells only wholesale products and is not packaging in consumer-sized containers, NLEA information is not required as the product is meant for wholesale distribution only. Fillets are considered a consumer-sized portion.

\section{Country of Original Labeling (COOL)}

The U.S. Department of Agriculture (USDA) issued its final rule regarding country of original labeling (COOL) on March 16, 2009.17 This rule requires "retailers to notify their customers of the country of origin of covered commodities." Wild and farm-raised fish and shellfish are included as requiring COOL labeling. For pre-labeled product, this information may be obtained directly from the label. For example, a label that includes the processor's address (as required by DEC regulations), and whether the product was wild or farm-raised, should be sufficient information for a retailer. ${ }^{18}$

14 Guidelines for the Voluntary Nutrition Labeling of Raw Fruits, Vegetables, and Fish, 21 CFR \$101.45 (2012). 15 Salmon Buyer's Guide, Alaska Seafood Marketing Institute, http://www.alaskaseafood.org/retailers/ practices/pages/buyerguide-salmon/index5.html (accessed February 2013); USDA National Nutrient Database for Standard Reference, http://ndb.nal.usda.gov/ (accessed February 2013). 


\section{References}

18 AAC 34, Seafood Processing and Inspection, http://dec.alaska.gov/commish/regulations/ pdfs/18\%20AAC\%2034.pdf (accessed February 2013).

Fish and Fishery Products Hazards and Controls Guidance (4th edn.), Food and Drug Administration, April 2011, http://ow.ly/fscY7.

U.S. Food and Drug Administration (FDA) Labeling and Nutrition, www.fda.gov/fod/ labelingnutrition/default.htm.

The Seafood List, FDA's Guide to Acceptable Market Names for Seafood Sold in Interstate Commerce (1993), http://ow.ly/fshi1.

\section{Acknowledgments}

I would like to personally thank the reviewers of this document, Mike Gentry of the Alaska Department of Environmental Conservation; Chuck Crapo, University of Alaska Fairbanks, Alaska Sea Grant Marine Advisory Program; and Brennan Smith, University of Alaska Fairbanks, School of Fisheries and Ocean Sciences.

\section{Legal Disclaimer}

This publication is for information only, and although the author refers to the Federal Code and Alaska statutes and administrative codes, this is not to be construed as legal advice. If you are unsure about the technical requirements for seafood labeling, processing, or marketing, please contact the Alaska Department of Environmental Conservation for the most up-to-date rules.

Author Izetta Chambers is an extension agent with the UAF Alaska Sea Grant Marine Advisory Program, based in Dillingham. She grew up in Alaska's Bristol Bay region and is the founder and seasonal manager of Naknek Family Fisheries, LLC, in Naknek, Alaska. Izetta conducts workshops on the National Environmental Policy Act (NEPA) procedures, fishing business start-up, seafood processing, Hazard Analysis Critical Control Point (HACCP), and fish waste composting.

Alaska Sea Grant is a marine research, education, and extension service headquartered at the University of Alaska Fairbanks School of Fisheries and Ocean Sciences. Alaska Sea Grant is supported by the National Oceanic and Atmospheric Administration Office of Sea Grant, Department of Commerce, under grant no. NA06OAR4170097 (projects A/161-02 and A/152-20), and by the University of Alaska with funds appropriated by the state.

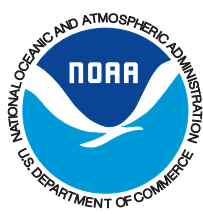
School of Fisheries and Ocean Sciences

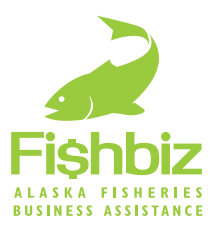

Marine Advisory Program University of Alaska Fairbanks 1007 West 3rd Ave., Suite 100 Anchorage, AK 99501

(907) 274-9691

map@sfos.uaf.edu

marineadvisory.org

\author{
Alaska Sea Grant \\ University of Alaska Fairbanks \\ PO Box 755040 \\ Fairbanks, AK 99775 \\ (888) 789-0090 \\ seagrant.bookstore@alaska.edu \\ alaskaseagrant.org
}

